\title{
Surface morphology variation during wet etching of GaN epilayer grown by HVPE
}

Dong Keun Oh, Bong Geun Choi, Suk Hyun Kang, So Yeon Kim, Sae Am Kim, Seong Kuk Lee*, Jin Hyun Chung*, Kyoung Hun Kim** and Kwang Bo Shim ${ }^{\dagger}$

Division of Materials Science and Engineering, Hanyang University, Seoul 133-791, Korea

*UNIMO Photron, Seoul 137-063 Korea

**Korea Institute of Ceramic Engineering and Technology, Seoul 153-801, Korea

(Received September 14, 2012)

(Revised September 27, 2012)

(Accepted October 5, 2012)

Abstract In this paper, we investigated characteristics of etching induced surface morphology variation by wet etching of GaN epilayer were grown on sapphire (0001) substrate by hydride vapor phase epitaxy (HVPE). As a results of scanning electron microscope (SEM) observation, three types of hexagonal etch pits (Edge, Screw, Mixed) were formed by the GaN epilayer thickness variations. A lot of etch pits, attributed to screw and mixed type TD, were observed at thinner epilayer, leading to high etch pit density. On the other hand, the thickness of GaN epilayer increased with the number of etch pits corresponding to edge and mixed dislocations, which are the majority of TDs are observed.

Key words GaN, HVPE, Etch pit, $\mathrm{H}_{3} \mathrm{PO}_{4}, \mathrm{LED}, \mathrm{LD}$

\section{HVPE법으로 성장시킨 GaN 단결정의 wet etching에 의한 표면 변화}

오동근, 최봉근, 방신영, 강석현, 김소연, 김새암, 이성국*, 정진현*, 김경훈**, 심광보

한양대학교 신소재공학과, 서울, $133-791$

*유니모포트론, 서울, $137-063$

**한국세라믹기술원, 서울, $153-801$

(2012년 9월 14일 접수)

(2012년 9월 27일 심사완료)

(2012년 10월 5일 게재확정)

요 약 본 연구에서는 HVPE법으로 사파이어 기판(0001) 위에 성장시킨 GaN epilayer의 etching에 따른 표면변화 특성 을 조사하였다. 주사전자 현미경(SEM) 관찰 결과, 3 가지 형태를 갖는 육각형 모양의 etch pit(edge, screw, mixed) 들이 GaN epilayer의 두께 변화에 따라서 형성되었다. 이러한 관통전위들은(TDs) epilayer의 두께가 얇고, etch pit density가 높을수록 screw and mixed type TDs이 많이 관찰되었고, 두께가 증가할수록 etch pit density가 낮아지면서 edge and mixed type TDs 들이 주로 존재하는 것을 관찰 할 수 있었다.

\section{1. 서}

$\mathrm{III}-\mathrm{V}$ 족 화합물중 $\mathrm{GaN}$ 는 넓은 에너지 간격 $(3.4 \mathrm{eV})$ 과 직접 천이형 밴드구조의 특성을 지니는 물질로서 $\mathrm{InN}$ $(\mathrm{Eg}=1.92 \mathrm{eV})$ 나 $\mathrm{AlN}(\mathrm{Eg}=6.2 \mathrm{eV})$ 와 같은 III-V계 질화 물 반도체와 연속적인 고용도를 가지므로 $\operatorname{In}_{\mathrm{x}} \mathrm{Ga}_{1-\mathrm{x}} \mathrm{N}$ 나

Corresponding author

Tel: +82-2-2220-0501

Fax: +82-2-2291-7395

E-mail:kbshim@hanyang.ac.kr
$\mathrm{Ga}_{\mathrm{x}} \mathrm{Al}_{1-\mathrm{x}} \mathrm{N}$ 과 같은 삼원계 질화물 고용체를 형성할 수 있어 가시광선 영역뿐만 아니라 자외선 영역을 포함한 거의 모든 파장대의 발광 소자를 제조할 수 있다. 이러 한 우수한 광학적 특성 외에도 열전도도가 크고 $(1.3 \mathrm{~W} /$ $\mathrm{cm})$, 고온에서 안정하며, 포화 전자 이동속도가 크고 화 학적으로 안정하여 고온, 고주파 영역에서 사용할 수 있 는 전자소자로도 응용이 기대되고 있다[1, 2].

그러나, $\mathrm{GaN}$ 단결정 기판은 제조의 어려움 때문에 사 파이어 나 $\mathrm{SiC}$ 기판을 이용하여 이종에피성장(heteroepitaxy)을 하게 되는데, 이때 격자상수 차이에 의해 
$\mathrm{GaN}$ epilayer에는 $10^{8} \sim 10^{10} \mathrm{~cm}^{-2}$ 정도의 많은 threading dislocation(TD) 들이 존재하게 된다[3]. 이러한 전위들은 전자와 정공의 재결합과정 (electron-hole recombination process)에서 비발광 중심(nonradiative center)로 작용하 기 때문에 LED 소자효율에 결정적인 영향을 미치게 된 다[4].

표면에 존재하는 $\mathrm{TD}$ 들을 관찰하기 위하여 전통적으로 chemical wet etching 법이 사용되어 왔다. $\mathrm{GaN}$ 의 경우 상온에서 화학적으로 매우 안정하지만, 고온에서 molten $\mathrm{KOH}$ 나 $\mathrm{H}_{3} \mathrm{PO}_{4}$ 와 같은 etchant에 쉽게 etching되어 표면 에 pit들이 형성된다[5].

최근 들어, $\mathrm{GaN}$ epilayer에 존재하는 관통전위들의 특 성을 평가하기 위한 방법으로 여러 가지 etchant들을 이 용하여 각각의 조건에 따라 생기는 etch pit의 모양, 크 기, etch rate, etch pit density 등을 분석하는 연구가 많 이 진행되고 있으며[6], 현재까지 연구된 바로는 etch pits 들은 nano-pipe[7] 형태로 생성되어, 일반적으로 mixedtype TD[8], screw-type TD[9], edge-type TD와 같은 3 가지 형태로 존재하는 것으로 보고되고 있다[10].

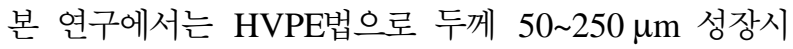
킨 $\mathrm{GaN}$ 단결정을 $\mathrm{H}_{3} \mathrm{PO}_{4}$ 를 이용하여 $200^{\circ} \mathrm{C}$ 에서 8 분간 etching 했을 때 $\mathrm{GaN}$ epilayer의 두께에 따라 형성되는 etch pit들의 모양과 etch pit density 사이의 상관관계를 비교분석 하였다.
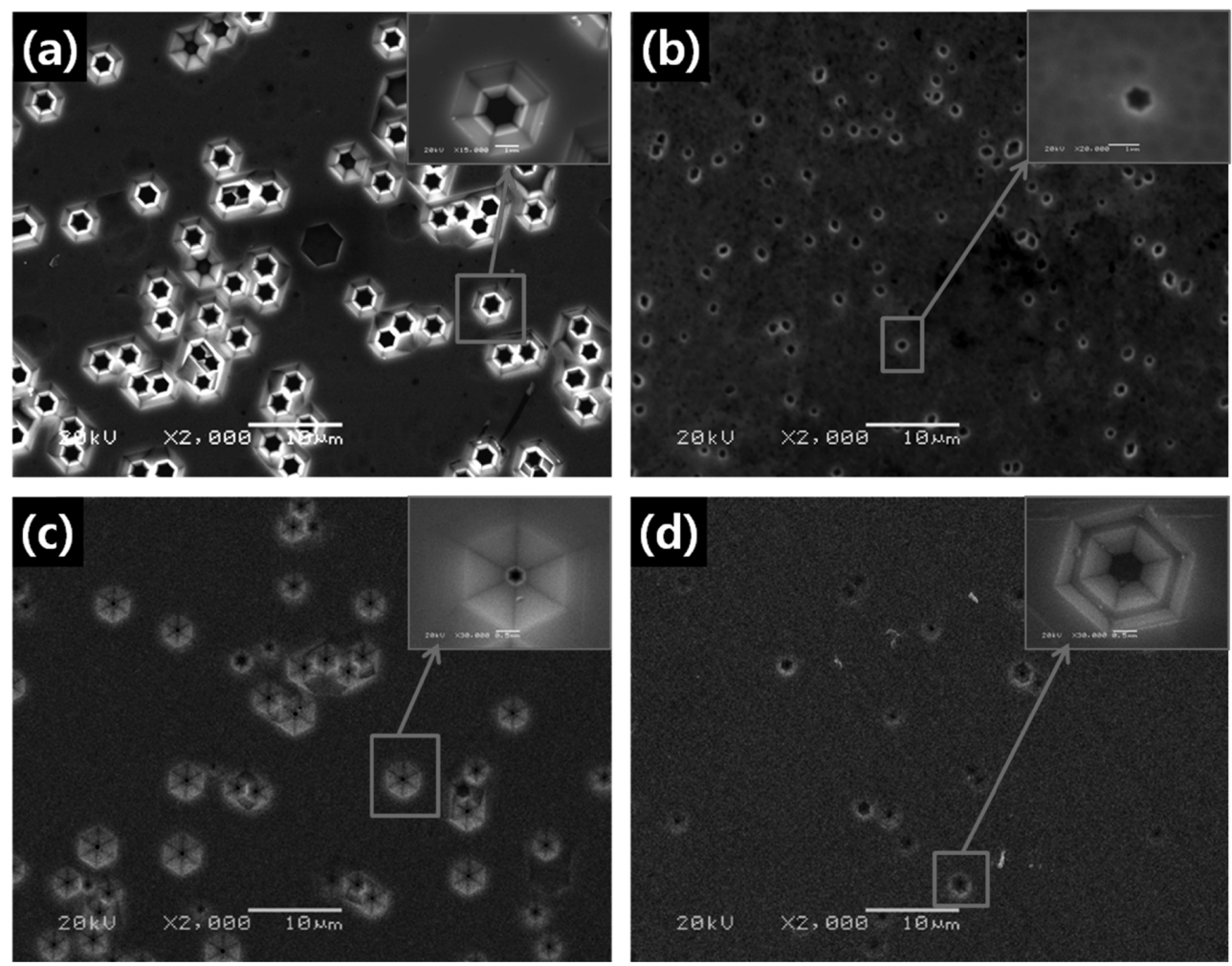

Fig. 1. GaN surface images of etched by $\mathrm{H}_{3} \mathrm{PO}_{4}$ (a) thickness $50 \mu \mathrm{m}$ (b) thickness $100 \mu \mathrm{m}$ (c) thickness $150 \mu \mathrm{m}$ (d) thickness $200 \mu \mathrm{m}$.

\section{2. 실 험}

자체 제작한 수직형 HVPE 장치를 이용하여 대기압 하에서 사파이어 기판(0001) 위에 $\mathrm{GaN}$ 층을 성장시켰 다. $\mathrm{Ga}$ 소스(source)로는 금속 $\mathrm{Ga}$ 을 $\mathrm{HCl}$ 가스에 반응시 켜 $700 \sim 800^{\circ} \mathrm{C}$ 에서 $\mathrm{GaCl}$ 을 형성하였고, $\mathrm{N}$ 소스로는 $\mathrm{NH}_{3}$ 가스가 사용되었고, carrier 가스로는 질소 가스가 사용되었다. $\mathrm{GaN}$ 결정의 성장온도는 $1000 ~ 1100^{\circ} \mathrm{C}$ 이었 으며, 성장속도는 $100 \mu \mathrm{m} / \mathrm{h}$ 를 유지하여 두께 $50 \mu \mathrm{m}$, $100 \mu \mathrm{m}, 150 \mu \mathrm{m}, 200 \mu \mathrm{m}$ 의 $\mathrm{GaN}$ 단결정을 각각 성장 시켰다.

성장된 $\mathrm{GaN}$ 단결정을 self-separation 법에 의해 사파 이어 기판을 제거한 후 diamond slurry를 이용하여 $\mathrm{Ga}-$ face 표면을 평탄화 하였고, $200^{\circ} \mathrm{C}, \mathrm{H}_{3} \mathrm{PO}_{4}$ 에서 각각 8 분 동안 etching 시켰다. Etching이 끝난 후 acetone, alcohol, $\mathrm{DI}$ water에서 각각 5 분간 세척하고, $\mathrm{N}_{2}$ 가스를 이용하여 건조 시켰다. Etching된 $\mathrm{GaN}$ 표면에 형성된 etch pit의 모양을 주사전자 현미경 $(\mathrm{SEM})$ 을 이용하여 관찰하였다.

\section{3. 결과 및 고찰}

Fig. 1에서 $200^{\circ} \mathrm{C}, \mathrm{H}_{3} \mathrm{PO}_{4}$ 에서 각각 8분 동안 etching 된 표면 $\mathrm{SEM}$ 사진을 보여주고 있다. 각각의 etch pit은 
(a)

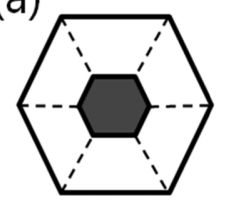

(b)
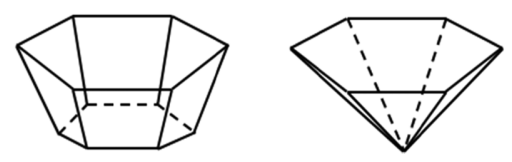

Fig. 2. Schematic view of shapes of etch pits (a) Screw-type TD (b) Edge-type TD (c) Mixed type TD.

육각형 형태를 띄고 있으며, 이 육각형의 etch pit을 좀 더 확대해서 살펴보면, 가장 밝은 부분은 가파른 급경사 를 이루고 있는 부분이고, 회색으로 보이는 부분은 완만 한 경사, 검은색 부분은 전자 현미경의 2 차 전자가 다다 르지 못해서 생겨난 홀(hole)로 보여진다. Fig. 1(b)를 도식적으로 나타내 보면 Fig. 2(a)에서 보여지듯이 etch pit의 모양은 끝을 자른 뒤집어진(inversed truncated) 육 각형의 모양을 띄고 있고, Fig. 1(c) 사진을 도식적으로 나타내면 Fig. 2(b)에서 보여지듯이 etch pit의 모양은 뒤집어진 피라미드 형태를 띄고 있다. Fig. 1의 (a)와 (d)의 사진을 도식적으로 나타내 보면 Fig. 2의 (a)와 (b)를 합쳐놓은 듯한 모양을 띠고 있다.
Hino et al.의 연구 결과에 따르면, Fig. 2(a)는 etchant 의 침투에 의한 표면에서부터 나선모양의 계단 구조를 형성하는 screw-type TD이며, Fig. 2(b)는 결함 주변의 원자들은 깨지기 쉬운 약한 dangling-bond를 이루고 있 기 때문에 표면과 수직으로 etching이 되어 뒤집어 놓은 피라미드 모양으로 etch pit가 형성되는 edge-type TD 이고, Fig. 2(c)의 경우 위의 (a)와 (b)가 혼재하는 mixedtype $\mathrm{TD}$ 이라 설명하였다[11].

Fig. 3의 SEM 사진은 두께에 따라 성장시킨 $\mathrm{GaN}$ epilayer의 표면을 etching한 cross-section 사진이다. Fig. 3(a)는 두께 $50 \mu \mathrm{m}$ 로 성장한 $\mathrm{GaN}$ 이며 etch pit 모 양은 Fig. 2(c) 모양과 흡사한 모습이다. 이때의 etch pit density는 $1.4 \times 10^{7} \mathrm{~cm}^{-2}$ 로 사파이어 기판과 $\mathrm{GaN}$ 사이 의 격자상수 차이로 인한 관통 전위들이 mixed-type $\mathrm{TD}$ 형태로 존재하고 있는 것으로 사료된다. Fig. 3(b)는 두께 $100 \mu \mathrm{m}$ 로 성장한 $\mathrm{GaN}$ 의 etch pit 모습을 나타내 고 있으며, Fig. 2(a)와 유사한 모양으로 대부분 screwtype TD 들이 존재하고, 이때의 etch pit density는 $6.5 \times$ $10^{6} \mathrm{~cm}^{-2}$ 이다. Hino et al.의 연구 결과에 따르면, 이러한 pure screw/mixed TD 들이 $\mathrm{GaN}$ epilayer에 비발광 중 심에 지배적으로 영향을 끼친다고 보고된다[9]. Fig. $3(\mathrm{c})$ 는 두께 $150 \mu \mathrm{m}$ 로 성장한 $\mathrm{GaN}$ 의 etch pit 모습을 나타내고 있으며, Fig. 2(b)의 모양과 흡사하며, 이때의 etch pit density는 $1.2 \times 10^{6} \mathrm{~cm}^{-2}$ 이다. $\mathrm{GaN}$ epilayer의
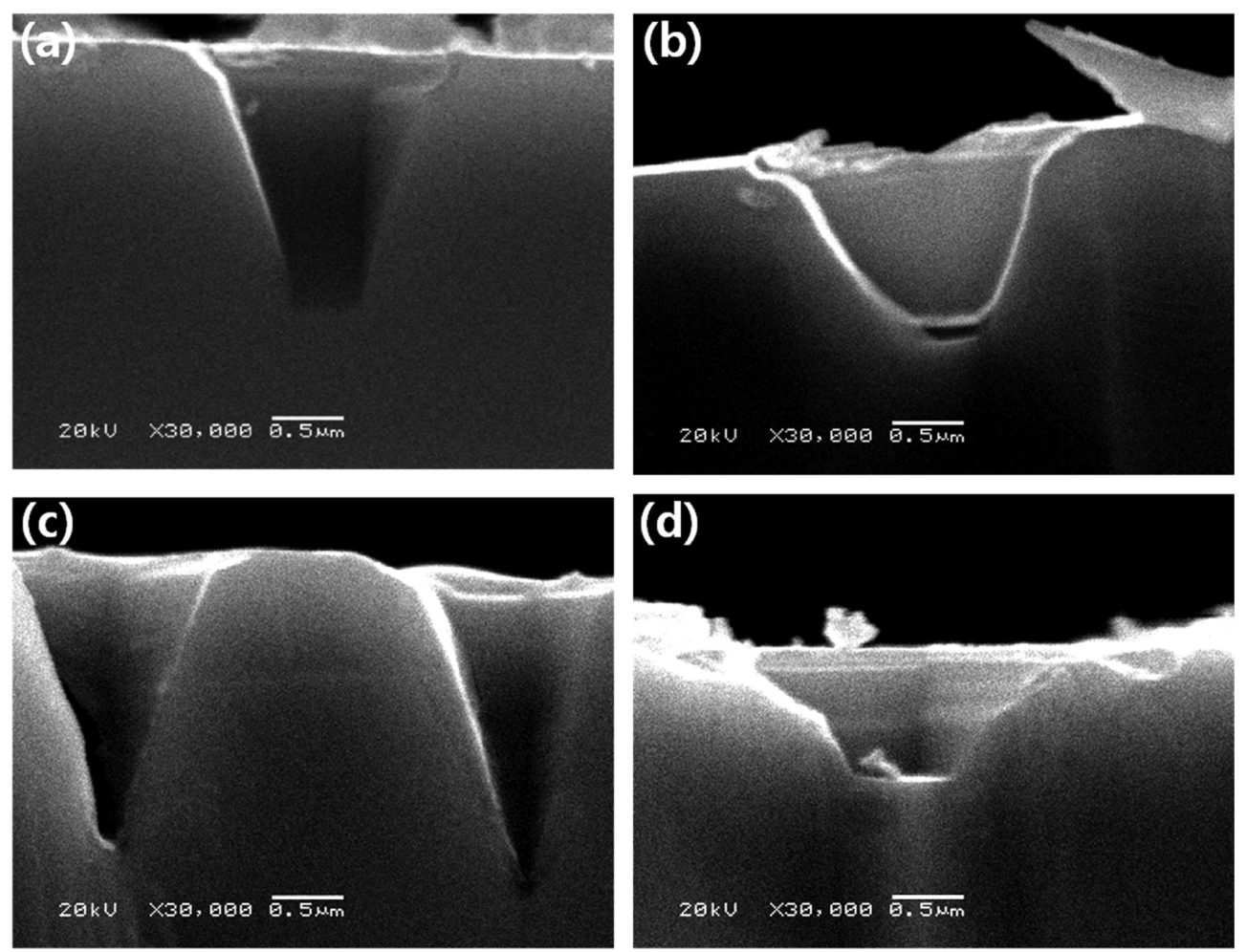

Fig. 3. GaN cross-sectional images of etched by $\mathrm{H}_{3} \mathrm{PO}_{4}$ (a) thickness $50 \mu \mathrm{m}$ (b) thickness $100 \mu \mathrm{m}$ (c) thickness $150 \mu \mathrm{m}$ (d) thickness $200 \mu \mathrm{m}$. 
두께가 증가할수록, etch pit density가 줄어들고 있으며, 소수의 screw, mixed-type $\mathrm{TD}$ 들이 관찰되지만 대부분 edge-type TD를 이루고 있는 모습이다. 하지만 Fig. 3(d)에서 두께 $200 \mu \mathrm{m}$ 로 성장한 $\mathrm{GaN}$ 이며 etch pit 모양 은 Fig. 2(c)의 모양과 흡사하게 mixed-type $\mathrm{TD}$ 들이 소 수로 존재하고 있었지만, edge-type $\mathrm{TD}$ 들도 관찰되고 있었다. 이때의 etch pit density는 $5 \times 10^{5} \mathrm{~cm}^{-2}$ 이었다.

\section{4. 결 론}

본 연구에서는 $\mathrm{GaN}$ epilayer의 두께에 따라서 달라지 는 etch pits의 모양들을 전자 현미경을 통하여 관찰하였 으며, 결함 밀도가 높을수록, screw/mixed-type $\mathrm{TD}$ 들이 지배적으로 관찰되었으며, 이후 $\mathrm{GaN}$ epilayer의 두께가 증가할수록 결함 밀도가 낮아지면서 소수의 edge-type $\mathrm{TD}$ 과 mixed-type $\mathrm{TD}$ 들이 존재하는 것을 관찰할 수 있 었다. 이러한 전위들은 $\mathrm{GaN}$ epilayer에서 발견되는 일반 적인 $\mathrm{TD}$ 들이며, 비발광 중심으로 작용하지 않는다, 하지 만 screw/mixed-type $\mathrm{TD}$ 들은 비발광 중심으로 작용하여 광학적 특성에 영항을 미쳐 LED 소자효율에 결정적인 영향을 끼치게 되므로 좀더 많은 연구가 필요할 것이다.

\section{감사의 글}

본 연구는 지식경제부 소재원천 기술개발 사업(과제번 호: 10041188)의 지원으로 이루어 졌습니다.

\section{참 고 문 헌}

[ 1 ] H. Morkoc, S. Strite, G.B. Gao, M.E. Lin, B. Sverdlov and M. Burnsl., "Large-band-gap SiC, III-V nitride, and II-VI ZnSe-based semiconductor device technologies", J. Appl. Phys. 76 (1994) 1363.

[2] D.K. Oh, B.G. Choi, S.Y. Bang, J.W. Eun, J.H. Chung, S.K. Lee, J.H. Chung and K.B. Shim, "Fabrication and characterization of GaN substrate by HVPE", J. Korean Cryst. Growth \& Cryst. Tech. 20(4) (2010) 164.

[ 3 ] S.G. Jung, H.S. Jeon, G.S. Lee, S.M. Bae, W.I. Yun, K.H. Kim, S.N. Yi, M. Yang, H.S. Ahn, S.W Kim, Y.M. Yu, S.H. Cheon and H.J. Ha, "The properties of AlGaN epi layer grown by HVPE”, J. Korean Cryst. Growth \& Cryst. Tech. 22(1) (2012) 11.

[4] S. Tomiya, E. Morita, M. Ukita, H. Okuyama, S. Itoh, K. Nakano and A. Ishibashi, "Structural study of defects induced during current injection to II VI blue light emitter", Appl. Phys. Lett. 66 (1995) 1208.

[ 5 ] D.A. Stocker, E.F. Schubert and J.M. Redwing, "Crystallographic wet chemical etching of GaN", Appl. Phys. Lett. 73 (1998) 2654.

[6] C.B. Vartuli, S.J. Pearton, C.R. Abernathy, J.D. MacKenzie, F. Ren, J.C. Zolper and R.J. Shul, "Wet chemical etching survey of III-nitrides solid-state electron", 41 (1997) 1947.

[ 7 ] S.K. Hong, B.J. Kim, H.S. Park, Y. Park, S.Y. Yoon and T.I.J. Kim, "Evaluation of nanopipes in MOCVD grown $\left(\begin{array}{llll}0 & 0 & 0 & 1\end{array}\right)$ GaN/Al2O3 by wet chemical etching", J. Cryst. Growth 191 (1998) 275.

[8] K.J. Hiojima, "Atomic force microscopy and transmission electron microscopy observations of $\mathrm{KOH}$-etched GaN surfaces", Vac. Sci. Technol. B 18 (2000) 37.

[9] A. Vennemann, J. Dennemarck, R. Kröger, T. Böttcher, D. Hommel and P. Ryder, "TEM investigation of defect reduction and etch pit formation in GaN", Mat. Res. Soc. Symp. Proc. 798 Y5.22.1 (2003).

[10] L. Lu, Z.Y. Gao, B. Shen, F.J. Xu, S. Huang, et al., "Microstructure and origin of dislocation etch pits in GaN epilayers grown by metal organic chemical vapor deposition", J. Appl. Phys. 104 (2008) 123525.

[11] T. Hino, S. Tomiya, T. Miyajima, K. Yanashima, S. Hashimoto and M. lkeda, "Characterization of threading dislocations in GaN epitaxial layers", Appl. Phys. Lett. 76 (2000) 3421. 